\title{
A mediação de diálogos com heterogeneidade de linguagens entre Formadores de Professores e o processo de construção de um aplicativo móvel para o Ensino de Química
}

\author{
Otávio Torreão Vasconcelos Gaião, Universidade Federal de Rondônia UNIR, Brasil \\ Liliane da Silva Coelho Jacon, Universidade Federal de Rondônia UNIR, Brasil \\ Ana Carolina Garcia de Oliveira, Universidade Federal de Rondônia UNIR, Brasil \\ Irene Cristina de Mello, Universidade Federal do Mato Grosso UFMT, Brasil
}

\begin{abstract}
Resumo: A possibilidade de acessar e produzir informações utilizando dispositivos móveis com acesso à Internet e conexão sem fio está revolucionando o funcionamento de diversas instituições, entre elas, a escola. No entanto, a chegada dessa tecnologia exige habilidades do professor, desafiando-o a reformular a sua prática de ensino para uma efetiva aprendizagem. Este artigo apresenta os resultados parciais de uma pesquisa exploratória, baseada nos pressupostos teóricos de Bakhtin, que teve por objetivo analisar as linguagens pluridirecionadas da interação dialógica entre uma formadora de professores de química e uma pesquisadora de informática e educação, visando discutir e refletir sobre o emprego da mobilidade na educação química. Estes encontros possibilitaram a emersão de novas ideias e, decorrente destas reflexões, apresenta um aplicativo (em fase de construção) intitulado "Laboratório Virtual de Química" que simula a realização de experimentos químicos focando reações de precipitação no estudo das relações estequiométricas.
\end{abstract}

Palavras-chave: diálogos, dispositivos móveis, formadores de professores, linguagens

\begin{abstract}
Summary: The possibility to access and produce information using mobile devices connected to the Internet and wireless connection is revolutionizing the functioning of various institutions, among them, the school. Nevertheless, the arrival of this technology requires teacher's skills, as it challenges them to rethink their way of teaching for effective learning. This article presents partial results of an exploratory study, based on Bakhtin's theoretical framework, who aimed at analyzing the "pluridirecionadas" languages of interaction between a professor for Chemistry students who are aiming for a teaching career and a research professor of computer science and education, to discuss and reflect on the use of mobile devices in chemical education. These meeting enabled the emergence of new ideas and presents an application (under construction) called "Virtual Chemistry Laboratory" which simulates chemical experiments focusing on precipitation reactions in the study of stoichiometric ratio.
\end{abstract}

Keywords: Dialogues, Mobile Devices, Teacher Trainers, Languages

\section{Introdução}

$\mathrm{N}$ as últimas décadas assiste-se a um acentuado movimento de transformação nas organizações sociais, impulsionado pelos avanços científicos e por um crescente desenvolvimento tecnológico. A conexão, muito além da rede mundial de computadores, passou a ser entendida como uma rede entre pessoas. E, neste cenário, os dispositivos móveis despontam-se como os protagonistas na garantia de um recurso favorável à conexão, minimizando sobremaneira as limitações espaço-temporais dos sujeitos.

Aprende-se com mobilidade (enquanto se está em movimento), quando pessoas aproveitam os mais diferentes locais, a qualquer horário, para desenvolver atividades que envolva aprendizagem, sejam elas de maneira formal (escolas, faculdades) ou informal (empresas, organizações) (Saccol et al., 2012, p.5). Parece natural, portanto, que em tempos atuais, exista um apelo cada vez maior para a inclusão de dispositivos móveis em sala de aula, tais como os tablets, celulares, smartphones, entre outros, disponibilizados com o intuito de melhorar o aprendizado e as práticas de ensino.

Revista Internacional de Aprendizaje en Ciencia, Matemáticas y Tecnología

Volumen 3, Número 1, 2016, <http://sobrelaeducacion.com>, ISSN 2386-8791

(C) Global Knowledge Academics. Otávio Torreão Vasconcelos Gaião et al.

Todos os direitos reservados. Permisos: soporte@gkacademics.com 
Repensar a educação a partir dessa realidade, e dos desafios que ela traz consigo, requer a compreensão da função docente diante das possibilidades oferecidas pela informática educativa e, em especial, os dispositivos móveis no contexto escolar. Um das principais dificuldades é devido ao pouco incentivo à incorporação de tecnologias nos currículos dos cursos de formação inicial (licenciaturas). É preciso realizar processos de reforma educacional na formação inicial que resultem em modificação das práticas dos formadores na preparação destes futuros professores, visando incorporar essa tecnologia móvel. Desta forma, surgem alguns questionamentos: Como um formador de professores pode empregar pedagogicamente essa tecnologia de conexão à rede sem fio e o uso de dispositivos móveis em sua prática escolar e, em especial, no ensino de química? Vale lembrar que a aproximação entre professor e tecnologia deve ocorrer, de preferência, nas licenciaturas e nos cursos de pedagogia.

Uma possibilidade para viabilizar esta "aproximação" com os professores formadores é a realização de encontros com profissionais de informática para discutir, refletir e dialogar sobre a incorporação dos dispositivos móveis no processo de ensino-aprendizagem. Nesta contextura, parte-se do pressuposto que a relação entre esses educadores e profissionais de informática deve ser a de parceiros solidários, que enfrentam desafios e se apropriam da cooperação e da criatividade para tornar a aprendizagem colaborativa, significativa, crítica e transformadora, a fim de que daí possam emergir ideias e propostas.

Nesta pesquisa, duas educadoras, uma delas formadora de professores de Química e a outra, professora pesquisadora de informática e educação, aceitam o desafio em promover encontros numa perspectiva dialógica, com o objetivo de construir atividades didático-pedagógicas utilizando dispositivos móveis. Decorrente destes diálogos, a professora pesquisadora de informática e educação, orienta um aluno de graduação em licenciatura em Informática, a construir um aplicativo para dispositivos móveis (plataforma Android).

\section{A mediação dos diálogos com heterogeneidade de linguagens: a contribuição da teoria bakhtiniana}

Um dos aspectos mais inovadores da produção de Mikhail Bakhtin foi enxergar a linguagem como um constante processo de interação mediado pelo diálogo e não apenas como um sistema autônomo. O sujeito se constitui no processo de interação com outros sujeitos, com outros discursos; e ao se constituir se modifica, se altera (Ferreira, 2012). E é neste processo de interação entre interlocutores que a linguagem se estabelece. Para Bakhtin, a verdade não se encontra no interior de uma única pessoa, mas está na interação dialógica entre pessoas que a procuram coletivamente. Ao falar, o interlocutor modifica, acrescenta, exclui, torce os significados codificados pela língua.

Dialogismo, segundo o dicionário Houaiss, significa a "arte de dialogar". Neste processo, busca-se compreender o sujeito da pesquisa, mas é fundamental que se trabalhe a diferença do lugar entre a pessoa que olha/fala e a pessoa que vê/escuta, incluindo a bagagem teórica e as concepções de cada um.

$\mathrm{Na}$ teoria bakhtiniana, o dialogismo pode ser interpretado como o elemento que instaura a natureza interdiscursiva da linguagem, na medida em que diz respeito "ao permanente diálogo, nem sempre simétrico e harmonioso, que existe entre os diferentes discursos que configuram uma comunidade, uma cultura, uma sociedade" (Brait, 1997, p. 98). Quando há um comprometimento de parceria entre os interlocutores, permeado por um constante diálogo, permite que se criem espaços onde o sujeito possa refletir sobre o seu pensar. Esta interação propõe que não haja uma fusão de vozes, mas que o caráter do diálogo permita que duas vozes sejam ouvidas (Bakhtin, 2006).

A heterogeneidade das linguagens pluridirecionadas entre interlocutoras da Educação Química e da Informática compreende o reconhecimento das seguintes linguagens:

- Linguagem Química: Os profissionais desta área de conhecimento utilizam representações químicas como forma de comunicação entre eles. Um fenômeno pode ser representado por símbolos, fórmulas e equações químicas. As representações químicas utilizadas para comunicação entre os profíssionais químicos são metáforas, modelos ou constructos teóricos da interpretação química da natureza e da realidade (Giordan, 2008, p. 179). A linguagem química é constitutiva do pensamento químico, que se configura como capacidade de inter- 
pretar, explicar e prever fenômenos químicos que rodeiam e afetam a humanidade (Schnetzler, 2002, p.16)

- Linguagem Computacional: O gênero discursivo dos profissionais da área computacional é incorporado, de forma crescente, no cotidiano dos cidadãos em um contexto de mundo globalizado da Sociedade da Informação. Os atos de informar, comunicar, acessar, produzir, manipular e armazenar informações na contemporaneidade exige, de seus cidadãos, a utilização de um gênero discursivo específico em uma sociedade em crescente transformação devido ao uso de Tecnologias Digitais. O sujeito, ao se expressar e socializar seus pensamentos, pode fazer uso de artefatos tecnológicos tais como os dispositivos móveis. A percepção do sujeito da sua realidade, quando armazenada em meio digital, pode ser expressa em vários formatos distintos: texto, áudio, imagem, animação, efeitos especiais e vídeos. A esta montagem de conexões em rede das ideias e pensamentos, expressas em formatos/mídias distintas tais como texto, imagem, imagem em movimento, música, voz, ilustrações, denomina-se linguagem hipermidiática (Paz, Neves e Alves, 2012).

- Linguagem Educacional: $\mathrm{O}$ gênero discursivo dos educadores reflete o período de formação do profissional. Provavelmente àqueles cuja formação foi nas décadas de 70 a 80 refletem um discurso tecnicista (Pereira, 2006, p.16; Richit, 2010,p.40); àqueles formados nas décadas de 80 a 90 possivelmente demonstram um discurso compromissado com a transformação da realidade social (Pereira, 2006, p.27; Richit, 2010,p.40) e, finalmente, àqueles formados após a década de 90 em diante, tendem para um gênero discursivo que ressalta a importância do professor reflexivo, daquele que pensa-na-ação (Richit, 2010,p.41; Garrido, 2006, p.619).

\section{Os dispositivos móveis no contexto escolar}

Muitos alunos que estão na escola e/ou na universidade conhecem e utilizam as tecnologias móveis, possivelmente por fazerem parte da geração de nativos digitais. A geração de jovens e adolescentes que nasceram na época em que os computadores já estavam plenamente disseminados, ou seja, após 1982, são denominados 'nativos digitais'. Esta geração faz uso massivo de tecnologia especialmente àquelas com possibilidade de conexão sem fio a Internet, exigindo novas práticas de aprendizagem na educação contemporânea (Saccol et al, 2012, p.21). A questão não é apenas priorizar o uso de aparelhos móveis ao invés de computadores (desktop) que não oferecem mobilidade, mas o fato que esta geração cresceu junto com a popularização dos aparelhos móveis e isto representa um ponto de vista diferente.

Lima e Loureiro (2012, sp) afirmam que "[...] alguns deles usam isto em seu dia a dia com muita desenvoltura. E o professor? Como o docente recebe esta situação em sala de aula?" Estes autores defendem que o professor precisa estabelecer conexões e integração entre seus saberes e os dos alunos e, também, que na formação de professores a utilização de tecnologias é muito importante para estimulação de outras formas de fazer docente.

O professor, ao repensar sua prática, deve considerar a mediação partilhada devido à característica coautoral dos dispositivos e a interface digital de natureza hipermidiática (Paz, Neves e Alves, 2012). A dinâmica da comunicação professor-aluno mediada por dispositivos móveis possibilita o mapeamento, o acesso, a manipulação, a criação, a distribuição e o compartilhamento de informações e conhecimentos a qualquer tempo e espaço acessados por tecnologias em rede. A natureza hipermidiática desta comunicação móvel permite agregar texto, áudio, imagem, animação, efeitos especiais e vídeo, como forma de socializar pensamentos e percepções entre sujeitos de culturas e realidades distintas. Com o crescimento de redes interativas, a cada dia surgem novas formas de conexão que passam a ser de domínio quase imediato dos alunos nativos digitais.

$\mathrm{O}$ estudo de Bernardo (2013) evidencia que o aproveitamento eficaz de m-learning no aspecto educacional pode conduzir à revisão da atitude e da prática pedagógica, sintonizando o ensino com a cultura digital. Ele conclui que é necessário um repensar docente diante da aceitação e do uso efetivo dos 
dispositivos móveis digitais no processo educacional, instigando reflexões, ações e mudanças (Bernardo, 2013).

No ensino de química, o grupo de pesquisa Intera, da Universidade Federal do ABC em São Paulo desenvolveu a ferramenta iLaboratory que atua como um simulador de laboratório para reprodução de alguns experimentos de química, de forma interativa, através de dispositivos móveis (Ramos et al., 2013, p.285-294). Ainda na área de ensino de química utilizando dispositivos móveis, o trabalho de Castro e Fernandes (2013) apresenta um ambiente de ensino de química orgânica baseado em Gamification (game com opção de jogar na web ou baixar no celular do estudante) cujos temas são as reações básicas de química orgânica como adição e substituição (Castro e Fernandes, 2013).

\section{Metodologia}

O percurso deste trabalho compreende duas etapas: primeiro, os diálogos entre uma formadora de professores de educação Química e uma pesquisadora de Informática e Educação, decorrente dos encontros para discutir o emprego dos dispositivos móveis no ensino de química, e que apresentam resultados parciais do doutorado da pesquisadora de Informática e Educação. Posteriormente, em uma segunda etapa, compreende a orientação de um trabalho de conclusão de curso de graduação de um aluno do curso de licenciatura e bacharelado em Informática no processo de implementação/codificação do aplicativo "Laboratório Virtual de Química". Vale ressaltar que, a construção deste aplicativo está em andamento e envolve o encontro periódico entre os envolvidos para rediscutir esta aplicação móvel.

\section{Primeira etapa: encontros para discutir o emprego da mobilidade no Ensino de Química}

A opção metodológica desta primeira etapa fundamentou-se na abordagem qualitativa referendada como pesquisa ação e foi baseada nos pressupostos teóricos de Mikhail Bakhtin. Esta estratégia foi utilizada nesta pesquisa, pois não se limita apenas a compreender e interpretar os diálogos, mas preocupa-se também com a mudança da prática pedagógica das educadoras envolvidas.

O local dos encontros entre as educadoras foi uma sala onde funciona o Laboratório de Ensino de Ciências - EDUCIENCIA da Universidade Federal de Rondônia (UNIR), campus de Porto Velho/RO. Nesta etapa, os sujeitos envolvidos foram: a professora formadora, doravante denominada PFQ, do departamento de Química da UNIR. Possui graduação em licenciatura e bacharelado em Química e mestrado em Educação pela Universidade de Campinas (UNICAMP). Na época dos encontros desta pesquisa, estava finalizando seu doutorado em Educação, também pela Unicamp; e a professora pesquisadora de informática e educação, doravante denominada PPIE, do curso de Licenciatura e Bacharelado em Informática da UNIR e doutoranda em Educação em Ciências e Matemática da Rede Amazônica de Educação em Ciências e Matemática REAMEC.

Os diálogos empreendidos entre as educadoras foram realizados entre 3 de dezembro de 2012 até o dia 7 de maio de 2013 (último encontro). Foram realizados dez encontros, que foram gravados e transcritos. Os encontros tinham por finalidade o enriquecimento acadêmico mútuo e os assuntos tratados foram os seguintes: cultura digital, formação inicial, construção de material e de atividades pedagógicas utilizando dispositivos móveis no ensino de Química, mobilidade e estratégias de ensino. Durante estes encontros foram realizadas duas atividades pedagógicas com os alunos de PFQ (Jacon et al., 2014a e JACON et al., 2014b), bem como o surgimento de ideias para construção do aplicativo "Laboratório Virtual de Química"

A interlocutora PPIE não possuia conhecimento técnico de Química e, tampouco, da linguagem que é empregada na comunicação entre os profissionais desta comunidade. Já PFQ emprega e utiliza no seu cotidiano pessoal e profissional diversos equipamentos tecnológicos, tais como: computadores portáteis, smartphone e tablet; sendo que os dispositivos móveis ainda não eram utilizados de forma pedagógica, no início da pesquisa. Cabe ressaltar que, devido ao fato das interlocutoras serem doutorandas em Educação, ambas privilegiam modelos de formação nos quais os professores são valorizados como sujeitos criativos e produtores sobre a prática docente. 
Nos encontros, o dialogismo constitui-se de enunciados que o precedem e o sucedem na cadeia de comunicação, ou seja, um enunciado solicita uma resposta e essa resposta pode ser de concordância ou de refutação. A sequência de enunciados abaixo mostra a comunicação das interlocutoras com o objetivo de elaborar de um software interativo para mostrar o processo de precipitação do iodeto de chumbo II, a partir da reação entre diferentes quantidades de iodeto de potássio com nitrato de chumbo II.

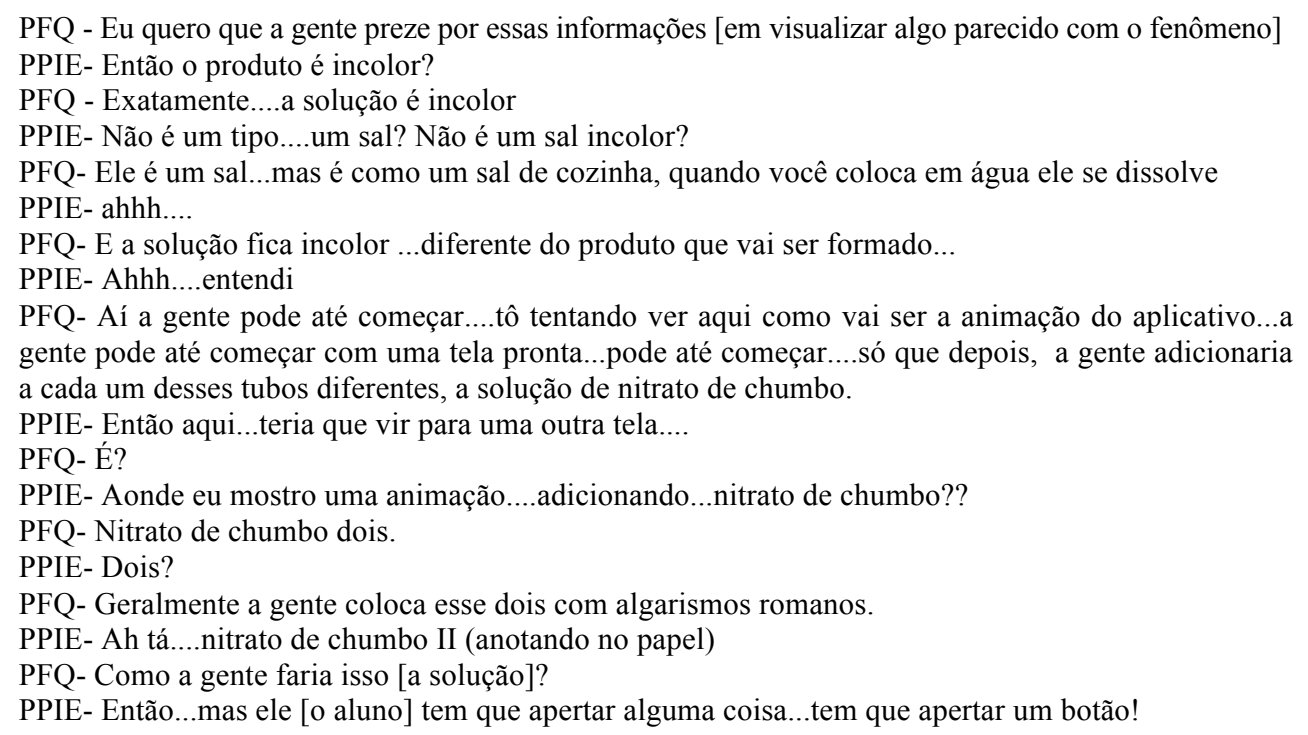

Nestes diálogos, o desafio no processo de interação entre as interlocutoras foi superar a falta de domínio da linguagem química de PPIE. Para isto, PFQ fez analogias para tornar compreensível sua fala, conforme a sequência de enunciados a seguir:

PFQ- Vão ter diferentes quantidades.....a gente juntou diferentes quantidades de iodeto de potássio com nitrato de chumbo e vai formar diferentes quantidades do sal.

PPIE- Quer dizer.....esse daqui que me deixou intrigada óhh [mostrando a figura no livro] Porque se eu misturar 10 [ml] de iodeto de potássio com 2 de nitrato de chumbo, deu um precipitado, mas se eu juntar 8 de iodeto de potássio com 4 de nitrato de chumbo eu [vou ter] tenho o maior precipitado?

PFQ- Porque a gente vai estar trabalhando com proporções ....eu vou voltar com a analogia do bolo.... não adianta....se uma receita de bolo vai $1 \mathrm{~kg}$ de farinha e 4 ovos, não adianta ter 4 ovos e $10 \mathrm{~kg}$ de farinha...

PPIE - Hum..

PFQ - é mais ou menos isso que acontece aqui... a gente precisa de quantidades ideais de nitrato de chumbo com iodeto de potássio. Não adianta você ter muito mais do outro ou muito mais de um....vai ter uma quantidade ideal ....isso é visto em estequiometria...são as proporções da reação.

A emersão de ideias só foi possível mediante o respeito às diferenças, buscando valorizar a pluralidade dos olhares e compreender a heterogeneidade das linguagens envolvidas.

\section{Segunda etapa: A construção do aplicativo "Laboratório Virtual de Química"}

Esta etapa apresenta o percurso no processo de orientação de um trabalho de conclusão de um aluno do curso de Licenciatura e Bacharelado em Informática da Universidade Federal de Rondônia UNIR. O desenvolvimento deste aplicativo, ainda em andamento, para a plataforma Android, teve/tem por objetivo simular um laboratório virtual para a realização de experimentos químicos focando nas relações estequiométricas de uma reação que envolve precipitação. Ou seja, o aplicativo possibilita estudar a relação entre diferentes quantidades de reagentes para formar os produtos em uma reação química. 
No caso desta pesquisa, tem-se uma simulação da reação entre o nitrato de chumbo II $\left[\mathrm{Pb}\left(\mathrm{NO}_{3}\right)_{2}\right]$ e o iodeto de potássio (KI), resultando na precipitação do iodeto de chumbo II $\left(\mathrm{Pbl}_{2}\right)$, produto insolúvel em água (Mortimer e Machado, 2010, p.230). Para isto, na simulação utiliza 5 tubos de ensaios, cada qual contendo uma quantidade diferente de iodeto de potássio, em uma mesma concentração de 0.5 $\mathrm{mol} / \mathrm{L}$. Adiciona-se nitrato de chumbo II, na concentração $0.5 \mathrm{~mol} / \mathrm{L}$, também em diferentes quantidades, em cada tubo de ensaio. As quantidades de cada reagente para cada tubo são especificadas na tabela 1, que ilustram a altura do precipitado de iodeto de chumbo (II), $\mathrm{Pbl}_{2}$, em função dos volumes de iodeto de potássio (KI) e de nitrato de chumbo (II) $\mathrm{Pb}\left(\mathrm{NO}_{3}\right)_{2}$ colocados.

Tabela 1: Altura do precipitado utilizados no experimento

\begin{tabular}{|l|c|c|c|}
\hline Tubo & $\begin{array}{c}\text { Volume da solução de KI } \\
(\mathrm{em} \mathrm{mL})\end{array}$ & $\begin{array}{c}\text { Volume da solução de } \\
\mathrm{Pb}\left(\mathrm{NO}_{3}\right)_{2}\end{array}$ & Altura do precipitado (em cm) \\
\hline 1 & 10 & 2 & 1,0 \\
\hline 2 & 8 & 4 & 2,5 \\
\hline 3 & 6 & 6 & 1,0 \\
\hline 4 & 4 & 8 & 0,8 \\
\hline 5 & 2 & 10 & 0.5 \\
\hline
\end{tabular}

Fonte: Mortimer e Machado, 2010.

Segundo o roteiro experimental, após a mistura, os tubos de ensaio devem ficar em repouso, por no mínimo 5 minutos, até que o precipitado esteja depositado no fundo. No fim do experimento, observa-se que as substâncias sempre mantêm a mesma proporção ao se combinarem, obedecendo a lei de Proust (Mortimer e Machado, 2010, p.234).

A figura 1 ilustra a tela inicial do aplicativo "Laboratório Virtual de Química", contendo 4 botões: Experimentos (animações no laboratório virtual); Teoria (base teórica textual); Avaliação (três questões que o aluno deve responder e que o aplicativo possibilita o envio das respostas via email para o professor de química) e Sobre (quem foram os idealizadores e desenvolvedores).

A teoria que contextualiza o processo de precipitação foi extraída do livro de "Química I: ensino médio" de Mortimer e Machado (2010), ilustrado na figura 2. A figura 3 ilustra as questões que o aluno deve responder, ao final do estudo, e que podem e devem ser enviadas (via email) para o professor responsável, ao clicar no botão "Enviar"

Figura 1: Tela inicial

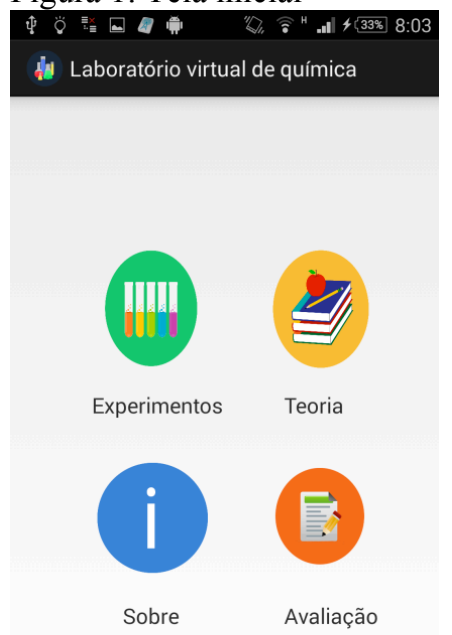

\section{3 ति 口}

Fonte: Gaião, 2014. 
Figura 2: Base teórica textual

4ै

Existe uma relação entre as quantidades de reagentes para formar os produtos de uma reação química?

Nesta atividade, tentaremos responder às questões feitas na introdução do capitulo, examinando algun dados obtidos em um experimento envolvendo a reação entre nitato de chumbo (II) $[\mathrm{Pb}(\mathrm{NO}) 2]$ e iodeto de potássio $(\mathrm{KI})$. 0 experimento foi escolhido para investigar essas questōes porque a reação entre o $\mathrm{Pb}(\mathrm{NO} 3) 2$ e o $\mathrm{KI}$ forma um produto insolúve em água, que se precipita na forma de um sólido amarelo. Se deixarmos o sistema em repouso, após adicionarmos os reagentes, o precipitado amarelo se deposita no fundo do tubo. Se, após isso,

medirmos, com o auxílio de uma régua, a altura do precipitado formado, teremos condições de comparar a quantidade de produto formado quando se misturam diferentes quantidades de reagentes. Para que pudéssemos efetuar essa comparação Para que pudessemos efetuar essa comparaç $\mathrm{Pb}$ (NO3) 2 e KI numa mesma concentração $(0,5 \mathrm{~mol} /$

L) Isso significa que num mesmo volume dessas L). Isso significa que, num mesmo volume dessas duas soluçoes, tem-se a mesma quantidade de um significado dessa ideia de "mesma quantidade" no significado dessa ideia de "mesma quantidad
texto 1 , após realizarmos esta atividade.

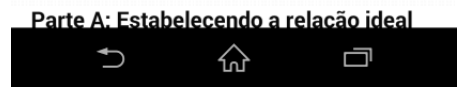

Fonte: Gaião, 2014.

Figura 3: Avaliação final que o aluno deve enviar ao professor

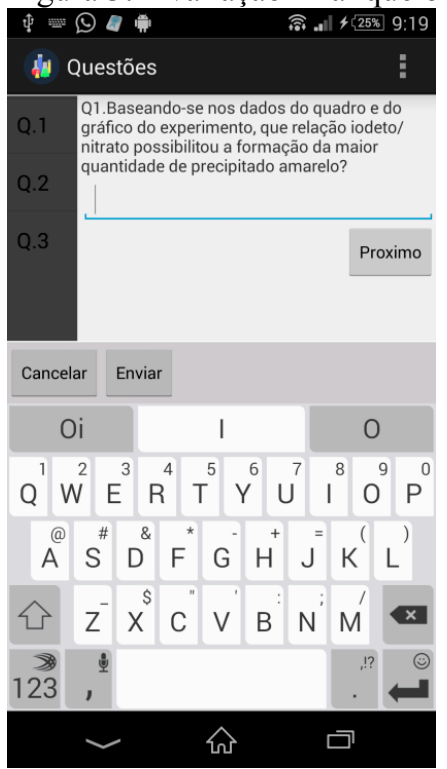

Fonte: Gaião, 2014.

A opção "Experimentos" da tela inicial (Figura 1) direciona para as telas contendo as animações (simulador da reação), ilustradas nas figuras 4,5 e 6 . A tela da figura 4 apresenta a animação de preenchimento dos tubos de ensaio com o primeiro reagente escolhido pelo usuário, no caso, nitrato de chumbo II. Já a figura 5 ilustra a situação final após a animação do preenchimento dos tubos de ensaio com o segundo reagente (iodeto de potássio). Repare que a figura 5 indica, no final da tela, que o usuário deve "chacoalhar" o dispositivo móvel para que a mistura ocorra. E a figura 6 ilustra o resultado da reação/ precipitação, após o usuário chacoalhar o equipamento. 
Figura 4: Tela que apresenta uma animação ( preenchimento dos tubos com o primeiro reagente escolhido)

䗆 Reagente 1

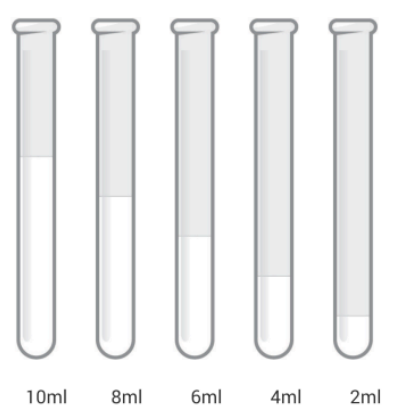

Reagente 1: Nitrato de chumbo (II) - $\mathrm{Pb}(\mathrm{NO} 3) 2$

Reagente 2: - -

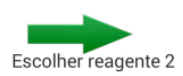

\section{5 ति $\square$}

Fonte: Gaião, 2014.

Figura 5: Tela após o preenchimento dos tubos com os dois reagentes

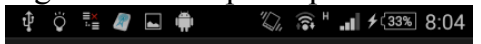

(1) Reagente 2

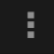

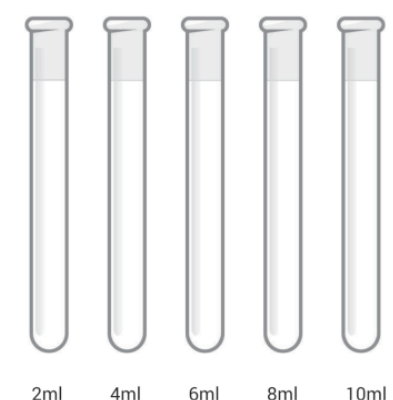

Reagente 1: Nitrato de chumbo (II) - $\mathrm{Pb}(\mathrm{NO} 3) 2$

Reagente 2: lodeto de potassio - (KI)

Chacoalhe para misturar

\section{$\rightarrow$ लि}

吕

Fonte: Gaião, 2014. 
Figura 6: Tela da reação final após o chacoalhar do dispositivo
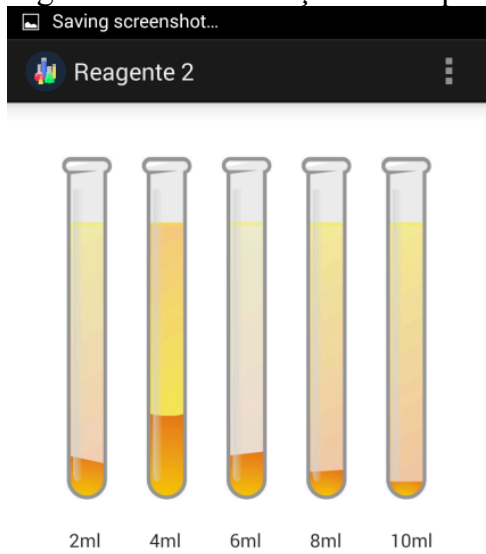

Reagente 1: Nitrato de chumbo (II) - $\mathrm{Pb}(\mathrm{NO} 3) 2$ Reagente 2: lodeto de potassio - (KI)

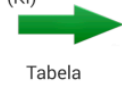

\section{$\rightarrow$ लि $\square$}

Fonte: Gaião, 2014.

Como o aplicativo encontra-se em construção, está sujeito à alterações conforme sugestão(ões) da Formadora de Professores de Química PFQ e da pesquisadora PPIE.

\section{Considerações}

Os encontros representaram momentos importantes de estudos teóricos sobre os dispositivos móveis e sua utilização na educação. Mas é importante ressaltar que, a incorporação dos dispositivos móveis na prática escolar das formadoras deve ser encarada como um processo continuado, que demanda tempo. Os formadores e consequentemente, os professores, necessitam de um período maior de amadurecimento para incorporá-las de forma profícua no processo de ensino aprendizagem.

O processo de incorporação pedagógica dos dispositivos móveis é muito mais um exercício de construção cultural, um processo de integração interpessoal entre docentes e discentes (alunos das licenciaturas), e de desenvolvimento de habilidades que irão se formar com o tempo e com a disponibilidade de colaboração entre eles. Uma base de conhecimentos sobre espaços de aprendizagem que possibilite extravasar a sala de aula física e presencial deve ser resultado da participação e colaboração interdisciplinar entre professores e discentes. Há muitas dificuldades que precisam ser vencidas, incluindo aí as iniciativas do uso desta tecnologia móvel na educação que ainda é uma novidade, tanto que várias escolas proíbem o uso destes dispositivos em suas dependências. 


\section{REFERENCIAS}

Bakhtin, M. (2006). Estética da criação verbal. São Paulo: Martins Fontes.

Bernardo, J. C. O. (2013). Dispositivos móveis digitais na incrementação do processo de ensino aprendizagem: Mobile learning no rompimento de paradigmas. Revista EDaPECI, 13(1), pp. 141-157.

Brait, B. (1997). Bakhtin e a natureza constitutivamente dialógica da linguagem. In: B. Brait (Org.), Bakhtin, dialogismo e construção de sentido. Campinas: UNICAMP.

Castro, F. S.; Fernandes, A. M. da R. (2013). Ambiente de ensino de química orgânica baseado em gamificação. In: congresso Brasileiro de Informática na Educação CBIE 2013 do XXIV Simpósio Brasileiro de Informática na Educação SBIE 2013. Unicamp, Campinas/SP.

Ferreira, H. M.C. (2012). A mediação dos dispositivos móveis nos processos educacionais. Revista eletrônica Teias, 13(30), pp. 209-226.

Garrido, E.; Brzezinski, I. (2006). A pesquisa na formação de professores. In R. L. L. Barbosa (org.), Formação de educadores: artes e técnicas - ciências e políticas (pp. 605-616). São Paulo: Editora Unesp.

Giordan, M. (2008). Computadores e linguagens nas aulas de ciências: uma perspectiva sociocultural para compreender a construção dos significados. Ijuí, RS: Ed. Unijuí.

Jacon, L. S.C.; Mello, I.C. de; Oliveira, A.C.G. de. (2014). Aprendizagem com Mobilidade no ensino de conhecimentos químicos: Reflexões de uma pesquisa realizada com professores em formação inicial. Revista Educação a Distância e Práticas Educativas Comunicacionais e Interculturais EDaPECI, 14(1), pp. 235-248. Disponível em: http://www.seer.ufs.br/index.php/edapeci.

Jacon, L. S.C.; Martines, E.A.L. de M.; Oliveira, A.C.G. de; Mello. (2014). Os formadores de professores e o desafio em potencializar o aprendizado em ciências químicas com a incorporação dos dispositivos móveis. Revista IENCI Investigações em Ensino de Ciências, 19(1), pp. 7789. Disponível em http://www.if.ufrgs.br/ienci/artigos/Artigo_ID356/v19_n1_a2014.pdf

Lima, L. de; Loureiro, R.C. (2012). O uso das TDIC na formação do professor universitário. In: Anais do III Seminário Web Currículo PUC-SP. Educação e Mobilidade, São Paulo.

Mortimer, E. F.; Machado, A. H. (2010). Química I: ensino médio. Sao Paulo: Scipione.

Paz, T.; Neves, I. B. da C.; Alves, L. (novembro, 2012). Constituição do currículo multirreferencial na cultura da mobilidade. In: Educação e Mobilidade. III Seminário Web Currículo Pontifícia Universidade Católica de São Paulo PUC-SP. São Paulo.

Pereira, J. E. D. (2006). Debates e pesquisas no Brasil sobre formação docente. In J. E. D. Pereira, Formação de professores: Pesquisas, representações e poder (pp. 15-52). Belo Horizonte: Autêntica.

Ramos, S.; Pimentel, E.; Braga, J. C.; Bertolini, C. T. (2013). Laboratório Virtual interativo para reprodução de experimentos de química através de dispositivos móveis. In: XXIV Simpósio Brasileiro de Informática na Educação SBIE 2013. Unicamp, Campinas/SP.

Richit, A. (2010). Apropriação do Conhecimento Pedagógico-Tecnológico em Matemática e a Formação Continuada de Professores (Tese de doutorado). Unesp, Rio Claro, SP.

Saccol, A.; Schlemmer, E.; Barbosa, J. (2011). M-learning e U-learning: novas perspectivas da aprendizagem móvel e ubiqua. São Paulo: Pearson Prentice Hall.

Schnetzler, R. P. (2002). Concepções e Alertas sobre formação continuada de professores de química. Rev. Química Nova na Escola, 16, pp. 15-20. 


\section{SOBRE OS AUTORES}

Otávio Torreão Vasconcelos Gaião: Graduado em Informática pela Universidade Federal de Rondônia, em 2014. Participou do Ciência sem Fronteiras em Computer Science Summer Course, Boston University, em 2013.

Liliane da Silva Coelho Jacon: Leciona no curso de Licenciatura e Bacharelado em Computação na Universidade Federal de Rondônia. Doutora em Educação pela Rede Amazônica de Educação em Ciências e Matemática-REAMEC (2014). Mestre em Computação pela Universidade Federal do Rio Grande do Sul UFRGS (2002) e Mestre em Educação pela Universidade do Oeste PaulistaUNOESTE (1998). Orientadora de trabalhos com ênfase em desenvolvimento de software na área educacional e Dispositivos Móveis.

Ana Carolina Garcia de Oliveira: Possui graduação em Química pela Universidade Estadual de Campinas (2004), mestrado em Educação (2008) e Doutorado em Educação (2014) pela mesma instituição. É membro do grupo de pesquisa da Universidade Estadual de Campinas. É professora Adjunto I da Universidade Federal de Rondônia (UNIR). Tem experiência na área de Educação, com ênfase em Currículo, Formação de Professores e Ensino de Química.

Irene Cristina de Mello: Concluiu o doutorado em Educação pela Universidade de São Paulo em 2003. Atualmente é Pró-Reitora de Ensino de Graduação da Universidade Federal de Mato Grosso. Professora lotada no Departamento de Química do Instituto de Ciências Exatas e da Terra. Coordena o Programa Institucional de Bolsas de Iniciação a Docência (PIBID/Edital 2009/UFMT) e o Programa PRODOCÊNCIA da UFMT. É professora do Programa de Pós-graduação em Educação da UFMT desde 2003. É professora do Mestrado Profissional em Ensino de Ciências da UFMT e do Programa de Pós-graduação em Educação em Ciências e Matemática, Doutorado da Rede Amazônica de Educação em Ciências e Matemática - REAMEC. 